\title{
Changes in peanut canopy structure and photosynthetic behavior resulting from arbuscular mycorrhizal association in a nutrient-poor environment
}

\section{Yinli Bi ( $\nabla$ ylbi88@126.com )}

China University of Mining and Technology (Beijing) https://orcid.org/0000-0002-5562-1045

Zhou huili

China University of Mining and Technology - Beijing Campus

\section{Perer Christie}

China University of Mining and Technology - Beijing Campus

\section{Research article}

Keywords: Arbuscular mycorrhizal fungi, canopy structure, photosynthesis, yield

Posted Date: July 16th, 2020

DOI: https://doi.org/10.21203/rs.3.rs-38568/v1

License: (c) (1) This work is licensed under a Creative Commons Attribution 4.0 International License.

Read Full License 
1 Changes in peanut canopy structure and photosynthetic behavior resulting from arbuscular mycorrhizal association in a nutrient-poor environment

$4 \quad$ Y L Bi ${ }^{a, b, *}$, H L Zhou ${ }^{a}$, Peter Christie ${ }^{b}$

6 Technology (Beijing), Beijing 100083, China

$7 \quad{ }^{b}$ College of Geology and Environment, Xi'an University of Science and Technology, Xi'an

$8 \quad 710054$, China

9

$10 *$ Corresponding author: Yinli Bi

11 E-mail address: ylbi88@126.com

12 Tel.: $+86(0) 1062339048$

13 Author 1:Huili Zhou

14 E-mail address: 1453648607@qq.com

15 Author 2:Peter Christie

16 E-mail address:drpeterchristie@aol.com

17 Abstract

18 Background:Well-developed canopy structure can improve the accumulation of biomass and yield of crops.In order to investigated the effects of arbuscular mycorrhizal fungi (AMF) on growth and canopy structure of peanut in a nutrient-poor environment,we inoculated plants with AMF and comparing plant temporal growth responses to those of uninoculated control plants.

Results: As time passed AMF increased plant height, crown width and total leaf area, decreased the tiller angle of the middle and upper canopy, increased the tiller angle of the lower canopy, reduced leaf inclination angle, and increased average leaf area and leaf area index. In addition, AMF increased the net photosynthetic rate, promoted plant nutrient uptake and the development of the plant canopy, thereby increasing the accumulation and yield of substances.

29 Conclusions:AMF and peanut can form beneficial symbiotic relationships.AMF colonization 
1 improved the canopy structure of peanut and thus further affected photosynthesis.

2 Keywords: Arbuscular mycorrhizal fungi, canopy structure, photosynthesis, yield

3

\section{Background}

Crop canopy structure is a major factor affecting photosynthesis and commonly involves the geometry, quantity and spatial distribution of various organs in the aboveground parts of a crop. More than $90 \%$ of the dry matter accumulation in plants is derived directly or indirectly from photosynthesis and the remainder is derived from nutrients taken up by the roots[1][2]. Canopy structure affects both the effective photosynthetic area of the leaves and aspects of the microenvironment such as temperature, humidity and $\mathrm{CO}_{2}$ concentration inside the canopy structure, thereby affecting crop photosynthetic efficiency and yield[3][4]. Canopy structure can be measured directly or indirectly based on leaf area index (LAI) and leaf angle distribution (LAD). Direct measurement is time-consuming, cumbersome, and destructive to plants[5]. The use of three-dimensional modeling methods to study the characteristics of crop canopy structure has recently become more popular. Riczu et al[6].established several plant branch models using an on-board laser scanner and compared the columnar branch model established in the Leica system, the 3D mesh tree model established using Geomagic software, and the trunk model using 3D shaping software. They believed that the latter two models were superior. Chang et al[2].established a three-dimensional canopy photosynthesis model of rice plants and used it to study the effects of three canopy structural parameters, namely tiller number, tiller angle and leaf angle, on the efficiency of canopy radiation. Xiang et al[7].established a non-destructive 3D scanning system using a commercial depth camera and Sorghum bicolor as an experimental species to continuously monitor plants of different heights and automatically extract their morphological characteristics.

Arbuscular mycorrhizal fungi (AMF) are a common group of soil microorganisms. They can form potentially symbiotic associations with most flowering plant species and have the potential to promote plant growth and to increase net photosynthetic rate[8][9][10]. AMF can effectively increase plant photosynthetic rate and leaf transpiration, thereby enhancing host plant carbohydrate content and significantly promoting plant yield and biomass[11]. AMF may increase plant photosynthesis, leaf area and chlorophyll content so as to increase plant 
1 biomass through various mechanisms. Wu et al[12]inoculated tea tree with AMF in the

2 laboratory and found that AMF inoculation vigorously promoted growth and significantly 3 increased the number of leaves, leaf stomatal conductance, transpiration rate, leaf chlorophyll content, net photosynthetic rate, and carbon sequestration capacity. Sheng et al[13]. found that inoculation of Zea mays with AMF under greenhouse conditions increased leaf biomass, chlorophyll content and net photosynthetic rate. AMF can stimulate root development, increase the nutrient and water absorption area, and improve root soil physical and chemical properties, thereby promoting plant growth and affecting plant external morphology[14][15]. Here, peanut was used as the experimental plant species and a handheld three-dimensional laser scanner and a portable photosynthesis instrument were used to monitor the dynamic effects of AMF on canopy structure and photosynthetic characteristics with the aim of determining the role of AMF on growth, canopy structure, photosynthesis and yield and to estimate plant photosynthetic capacity at later growth stages. The aim was to provide experimental data regarding the improvement of crop canopy structure and increasing dry matter accumulation and yield through AMF inoculation in nutrient-poor environments.

\section{Methods}

\subsection{Experimental materials}

The AMF strain Glomus versiforme BGC NM04B was used. The mycelium length was $3.12 \mathrm{~m} \mathrm{~g}^{-1}$ and the spore density was $26 \mathrm{~g}^{-1}$ substrate. The strain was obtained and purified at the reclamation laboratory, China University of Mining and Technology (Beijing). The peanut variety used was four red peanuts purchased from Hebei Xingnong Fumin Seed Sales Co. LTD.The voucher specimen of this peanut has not been deposited in a publicly available herbarium.The effects of bacterial inoculation on peanut growth in a nutrient-poor environment was explored using a river sand sterilized at high temperature as the test soil. The contents of available phosphorus and available potassium in the river sand were 1.25 and $41.3 \mathrm{mg} \mathrm{kg}^{-1}$, respectively, and the organic matter content was $2.71 \mathrm{~g} \mathrm{~kg}^{-1}$. 


\subsection{Experimental procedure}

The experiment was conducted at the outdoor Microbial Reclamation Laboratory, China University of Mining and Technology (Beijing). In detail, a total of 16 pots were randomly assigned to AMF and control groups with eight replicates per group. Each pot in the AMF group contained a mixture of $5 \mathrm{~kg}$ river sand and $50 \mathrm{~g}$ of AMF inoculum which was composed of AMF root segment and rhizosphere soil. Each pot in the control group contained the same mixture of sand and AMF inoculum but the inoculum was heat-sterilized to prevent mycorrhizal colonization. Five peanut seeds were sown in each pot on May 25, 2019. At the true leaf stage only one seedling was retained in each pot and pot was watered regularly based on its weight to maintain the water content at $70-80 \%$ of water holding capacity.

In addition, each pot was supplied with nutrient solution supplying $\mathrm{NH}_{4} \mathrm{NO}_{3}, \mathrm{KH}_{2} \mathrm{PO}_{4}$, and $\mathrm{KNO}_{3}$ to maintain the soil $\mathrm{N}, \mathrm{P}$, and $\mathrm{K}$ contents at 100,25 , and $150 \mathrm{mg} \mathrm{kg}^{-1}$, respectively. The plants were observed after growth for 30,45 and 70 days and harvested after 70 days. The aboveground and underground plant dry weights were determined by oven drying. In addition, $0.1 \mathrm{~g}$ of the ground, dried roots, stems and leaves were digested using a mixture of sulfuric acid and hydrogen peroxide. A portion of the samples was used to determine the total nitrogen content by the Kjeldahl method and another portion to determine the total nitrogen content by ICP-OES spectrometry. Some fresh fine root samples were collected and used for determination of total phosphorus and total potassium[16]. Moreover, a small amount of fresh fine root samples was randomly collected. After immersion in 10\% (w/w) KOH for $24 \mathrm{~h}$ and rinsing with water they were stained using acid fuchsin lactic glycerol solution as previously reported. Fifteen root sections were randomly selected, prepared as slices, and observed under a microscope to determine the AMF colonization rate[17].

\subsection{Examination of plant three-dimensional structures}

\subsubsection{General procedures}

The point cloud data of the three-dimensional canopy structure of peanut were obtained using a portable Creaform HandySCAN 700 three-dimensional laser scanner (Manchester Metrology Ltd, Ashton-under-Lyne, UK) with a scanning accuracy of $0.5 \mathrm{~mm}$ after 30, 45, 
and 70 days of growth in an indoor wind-free environment. After scanning the grid data were created and exported in STL format. The data were then processed using the Geomagic 2015 software application with the main steps of coordinate transformation, noise removal, model repair and data extraction to obtain an independent and complete three-dimensional plant model[14].

\subsubsection{Extraction of canopy data}

Plant height (cylinder height) and crown width (cylinder diameter) were extracted using the cylinder in the "Feature" tool as the smallest cylinder surrounding the plant[18]as shown in Fig. 1b. The total leaf area and average leaf area of different layers were calculated using the Selection and Measurement tools[14]. The planes where leaves were located were obtained using the method of best fit and the angle between the plane and the ground, i.e. the leaf inclination angle, was obtained using the measurement tool and the trigonometric function method[19]. The angle between the tiller and upright direction, i.e. the tiller angle, was calculated using the Measurement tool and trigonometric function method. The projected area was calculated using the supervised classification method in the grid background of the screenshot view. The ratio of the total leaf area to the projected area was used to calculate the leaf area index (LAI)[20]. In the intermediate and later growth stages the canopy was divided into upper, middle and lower layers according to the tiller height and leaf age (Fig. 1).

The plants reached peak photosynthesis at 10:00-13:00 on a day with sunny and stable weather. The stomatal conductance, intercellular $\mathrm{CO}_{2}$ concentration, transpiration rate and net photosynthetic rate of leaves at different layers were therefore determined on a clear and cloudless day using an LI-6400XT portable $\mathrm{CO}_{2} / \mathrm{H}_{2} \mathrm{O}$ analysis system (Li-COR Inc., Lincoln, $\mathrm{NE}$ ). The effective radiation of the light source PAR was $1000 \mu \mathrm{mol} \mathrm{m}^{-2} \mathrm{~s}^{-1}$, the leaf chamber used was $2 \times 3 \mathrm{~cm}$, and the gas flow rate was $500 \mathrm{mmol} \mathrm{s}^{-1}$. Three groups of leaves were determined randomly at each layer of each plant.

\subsection{Data processing}

Data were processed using Microsoft Excel 2010 and subjected to significance of 
1 difference analysis and correlation analysis using the IBM SPSS 20.0 statistical software 2 package.

\section{Results and analysis}

\subsection{Root colonization by AMF}

The roots were well colonized by AMF. After 70 days of growth the perecentage of root length colonized reached $95.4 \%$. No AMF colonization was observed on root samples from the control plants. The results indicate the presence of a potentially mutually beneficial relationship between AMF and the roots. This potentially symbiotic association may have influenced plant growth and development.

\subsection{Effects of AMF inoculation on canopy structure}

The canopy structure refers to the numbers and relative positions of stems and leaves above the ground. There are two types of indicators, namely non-complex and complex traits. The former are features extracted from the whole plant such as height, width, volume, and rough leaf area estimates and the latter describes the traits at organ level such as accurate leaf area, leaf inclination, tiller angle, and fruit count[18].

\subsubsection{Effects of AMF inoculation on non-complex traits of canopy structure}

At 30 days the mycorrhizal plants and non-mycorrhizal controls had the same growth rate but at 45 days the growth rate of AMF plants was significantly faster than that of the controls, indicating that $G$. versiforme promoted plant uptake and utilization of nutrients from the soil while the controls grew slowly due to nutrient deficiency with both plant height and total leaf area increasing gradually. After 70 days the mycorrhizal plants continued to grow. In contrast, although the plant height of the controls increased, their leaves withered due to nutrient deficiency. AMF inoculation promoted the growth of plants and increased the total area of leaves, thus increasing photosynthetic accumulation and further promoting their growth. The gap between the inoculated and control plants therefore gradually widened (Table 1).The results show that AMF promoted plant of nutrients with good canopy 
development.

\subsubsection{Effects of AMF inoculation on the complex characteristics of canopy structure}

According to the growth sequence of tillers, at 30 days the new tillers were divided into an upper layer and the old tillers into a lower layer. At 45 and 70 days the tillers were divided into upper, middle and lower layers as the number of tillers continued to increase (Table 2). There were no differences in bacteria and control plant height after 30 days of growth. However, there were subtle differences in configuration such as tiller angle and leaf angle on the inoculated plants withs the upper tillering angle significantly less than on control plants, a greater leaf angle than on the control plants, and a greater average lower leaf area than on the controls, suggesting that the plants were more upright after AMF inoculation (Table 2).

After 45 days of growth (Table 2), the tiller angles of the upper, middle, and lower layers in the AMF treatment gradually decreased in the sequence: upper, middle and lower layers, while those in the controls did not differ significantly from each other. In addition, the tiller angles in the upper and middle layers of the AMF treatment were significantly smaller than in the controls, while the lower part was larger than in the controls. These results indicate that the configuration of the plants in the AMF treatment was more optimal, similar to the semi-manifold characteristics of the lateral branches in the lower layer growing along the ground surface, and the lateral branches in the middle and upper layers grew upright[21][22]. In contrast, plants in the control group were poorly layered. The newly developed tillers had smaller tiller angles, and the above results indicate that there were more fresh tillers in the AMF treatment than in the control after 45 days of growth, suggesting the mycorrhizal plants grew more quickly than the controls. Moreover, the inclination angle of leaves in the upper, middle and lower layers of the AMF treatment was smaller than in the controls, indicating that the leaves of the inoculated plants were relatively flat, providing a larger area to receive solar radiation, and this would be conducive to photosynthesis. The average leaf area of the mycorrhizal plants was larger in the upper and lower layers than in the middle layer. This structure might reduce the shading of the lower leaves and increase light transmittance, again beneficial to photosynthetic activity. There was no difference in the average leaf areas among 
1 the three different layers of peanut in the controls (Fig. 2).

2 After 70 days of growth (Table 2) the tiller angle in the AMF treatment decreased gradually

3 from the upper to the lower layers but in the control was smaller in the upper layer, indicating that the control plants were still in the active growth phase but mycorrhizal plants were already at the mature stage and their growth had declined or halted. In addition, the inclination angle of the upper leaves in the AMF treatment was significantly smaller than that of the middle and lower layers because the upper leaves were larger, were unable to stand upright, and apparently bent and sagged. The configuration of the shoots in the AMF treatment formed a gradient of angles from top to bottom, indicating that the upper layer inclination angle was the smallest and the lower layer was the largest. The upper and lower leaves would not shade each other, thereby increasing the exposed leaf area. The total leaf area was also larger in the AMF treatment than that in the controls within the same layer and at the same time. The results are consistent with the changes in leaf inclination and tiller angle. Overall, mycorrhizal inoculation promoted a more functional and hierarchical canopy structure so as to optimize the structure for photosynthesis (Table 2).The average leaf area of the inoculation treatment increased with time, while nutrient deficiency in the intermediate and later growth stages of the controls led to smaller newly-produced leaves, and dead, yellow and old leaves. the average leaf area therefore tended to decline.

\subsubsection{Effects of AMF colonization on leaf area index}

Leaf area index reflects the status of plant growth and utilization of the light energy by the leaves[23]. Leaf area index is the ratio of the total leaf area to the projected area. During growth the total area of the leaves of inoculated plant increased rapidly but the canopy expansibility and the projected area also increased so that the leaf area index increased slightly. Leaf area index did not differ significantly between mycorrhizal and control plants after growth for 30 days. After growth for 45 and 70 days the leaf area index of AMF inoculated plants was significantly higher than that of the controls. When the index is $<5.5$ the larger the leaf area index, the higher the light interception and the greater the utilization of solar energy[24]. The maximum value of the leaf area index was $<5.5$ in both mycorrhizal plants and controls. At the intermediate and later growth stages the leaf area index of 
1 inoculated plants was higher than that of the controls, indicating that AMF treatment

2 increased the effective radiation utilization by the canopy.

After growth for 30 days (Table 3) the plants were short and their leaf area index was small. There was little difference between AMF plants and controls. Leaf area index gradually increased after 45 days and showed significant differences between mycorrhizal plants and controls. Later, the plants entered the mature stage. Their lower layer leaves and sheltered leaves gradually withered and the leaf area index began to decline. Overall, AMF inoculation increased the use of solar energy. These results are in accord with Wang et al. (2003).

\subsection{Effects of AMF treatment on plant photosynthetic characteristics}

\subsubsection{Effects of AMF treatment on net photosynthetic rate}

After 30 days of growth, peanut was short, and their canopy was divided into two layers according to the tillering time. At this time, the difference in net photosynthetic rate between different treatments and different layers was not significant. After 45 and 70 days of growth, the net photosynthetic rate showed the tendency of upper layer $\geq$ middle layer $>$ lower layer. The results indicated that the leaf structure plays an important role on the leaf net photosynthetic rate. There was no difference in net photosynthetic rate between different layers in the control treatment(Table 4). It is probably because that the control peanut grew slowly and were short, and different layers were not significantly different. In addition, the leave area index was low and the leaves in the middle and lower layers were blocked and had almost same light reception.

After growth for 45 and 70 days (Table 4) the leaf net photosynthetic rate at different positions was significantly higher in mycorrhizal than in non-mycorrhizal plants, indicating that AMF treatment increased the net photosynthetic rate of single leaves. After growth for 45 days, canopy growth reached a maximum in the AMF treatment. The plants then started to enter the fruit completion stage during which the leaves began to age and the photosynthetic rate decreased. By contrast, control plants grew slowly and their canopy still grew slowly until later stages and photosynthesis continued to increase. Therefore, the difference in the 
1 photosynthetic rate between the AMF plants and the controls reached a maximum at the 2 intermediate stage.

At later growth stages the utilization of light energy and the level of photosynthetic components determine pod fullness eventually. AMF treatment increased the net photosynthetic rate and also increased the leaf area for photosynthesis, thereby greatly increasing total accumulation of photosynthates, a major contribution to increasing peanut yield.

\subsubsection{Effects of AMF inoculation on other photosynthetic indices}

Water use efficiency (WUE) is the ratio between net photosynthetic rate and transpiration rate and is an important index of drought resistance. When water resources are scarce, WUE is an important means of assessing the contradiction between plant productivity and water consumption[25] (Zheng et al.,2019). Table 5 shows that after growth for 45 days the net photosynthetic rate, stomatal conductance and transpiration rate of the inoculated plants were all higher than those of the controls but WUE was lower than in the controls. Therefore, inoculation promoted root uptake of water and nutrients, increased photosynthetic rate, and supplied the cells of the plants with adequate water to meet the requirements of growth.

Stomatal conductance is a common foliar route of entry and exit of $\mathrm{CO}_{2}$ and water vapor but theoretically the diffusion resistance of $\mathrm{CO}_{2}$ is less than that of water vapor, thus the influence of stomatal conductance on photosynthetic rate is greater than that on transpiration rate. Studies show that WUE increases with decreasing stomatal conductance[26]. Here, the control plants showed a weak capacity to take up water and nutrients and a low intracellular water content compared with the inoculated plants. Stomatal conductance declined to meet the requirements for growth, resulting in a higher water use efficiency in the controls (Table $5)$. 


\subsection{Effects of AMF inoculation on plant nutrient uptake and biomass}

\subsubsection{Effect of AMF treatment on plant nutrient content}

Total nitrogen, phosphorus and potassium in leaves, stems and roots were significantly higher in the mycorrhizal plants than the controls (Table 6). These results are similar to those of Qiu et al. (2019) and indicate that AMF increased plant nutrient uptake to promote growth.

\subsubsection{Effect of AMF inoculation on plant biomass accumulation}

AFM treatment significantly increased dry matter accumulation and yield and substantially promoted plant growth $(\mathrm{p}<0.05)$ compared to the control. The results are similar to those of Xiao et al[15] and in accord with the changes in canopy structure. Mycorrhizal plant canopy structure was more developed than that of the controls. The leaf angle of the upper and lower layers can adjust to receive more light and increase the photosynthetic rate so as to enhance biomass and yield (Table 7).

\subsection{Correlation analysis between canopy structure and production}

Plant yield was significantly positively correlated with plant height, crown width and total leaf area at $\mathrm{P}<0.01$ but not significantly correlated with leaf area index, leaf obliquity or average leaf area, and was negatively correlated with tiller base angle (Table 8).

\section{Discussion}

Canopy structure directly affects the efficiency of photosynthesis. Changes in canopy structural characteristics of crops such as leaf area index and mean leaf inclination have a significant impact on the ability of the canopy to intercept photosynthetically active radiation[27] and also the microenvironment within the canopy (including temperature, humidity and light intensity)[3], and this affects crop photosynthesis and yield. AMF treatment makes the plant configuration more developed and increases the rate of photosynthesis. AMF treatment may affect root function first[28], facilitating the root system to take up more nutrients and transport them to the aboveground parts to support the stems to be straighter, the leaves more robust and the canopy to expand more broadly. Chen et 
1 al[29]found that under nutrient sufficiency conditions the canopy structure of Glycine max

2 was loose and conducive to the formation of yield factors. By contrast, under limiting nutrient conditions the canopy is blocked and this limits the formation of yield factors.

AMF treatment can effectively increase nutrient uptake[28], ensure adequate nutrition of the aboveground parts and foster to rationalization of the canopy structure, increase the efficiency of photosynthesis, and increase the synthesis of aboveground carbohydrates. The aboveground parts of mycorrhizal plants can transfer more carbohydrates to the roots, and the growth and development of AMF mycelia also require more materials such as carbohydrates to maintain their growth. Therefore, the configuration of the aboveground canopy structure can be more reasonably adjusted to achieve the process of converting light energy into chemical energy. AMF treatment can promote the absorption of $\mathrm{N}, \mathrm{P}, \mathrm{K}$ and other mineral elements from the soil by peanut[30], and these mineral elements constitute the compounds related to photosynthesis (e.g. $\mathrm{K}^{+}$can affect the transport and accumulation of photosynthetic products), thereby directly or indirectly affecting photosynthesis.

Peanut in the AMF treatment reached a maximum net photosynthetic rate at 45 days of growth and began to complete the transition from vegetative growth to reproductive growth. By contrast, nonmycorrhizal control peanut remained in the slow growth stage until 70 days. It is possible that the root system in the AMF treatment can take up more nutrients and transfer them to the aboveground parts. AMF colonization can alter the canopy structure of to use light energy more effectively. Almost all the carbon in AMF is derived from the photosynthetic products of the host plants[31]. The mycelia can utilize 4 to $20 \%$ of the photosynthetic products of the host plants[32] and this increases the demand of the host plants for carbon. Increased carbon demand by plants will further accelerate the tricarboxylic acid cycle in the photosynthetic reaction, regeneration of $\mathrm{RuBP}[33]$, transport of photosynthetic products to the aboveground parts, processing of photosynthetic reactions, and the photosynthetic rate of the plants. The utilization of photosynthetic products including sucrose and glucose by AMF promotes the transportation of sucrose from leaves to roots, thereby iincreasing photosynthesis. Wu et al[34]inoculated Citrus reticulata seedlings with $\mathrm{AMF}$ and found that sucrose and glucose contents in C. reticulata leaves were significantly 
1 positively correlated with the AMF colonization rate. The association between AMF and host

2 plants can accelerate the transport of photosynthetic products from leaves to roots, thereby

3 reducing the concentration of carbohydrates in the aboveground parts of plants, stimulating photosynthesis by plants to meet their own growth needs, and increasing $\mathrm{CO}_{2}$ fixation. This may be because AMF promote the transport of tricarbonose in plants, accelerate the Pi cycle, and further accelerate the tricarboxylic acid cycle, thus enhancing plant photosynthetic ability[35]. AMF can enhance the nutritional status of plants, carbon fixation[36], organic matter synthesis and accumulation, and carbon transport, fixation and cycling in the ecosystem.

A suitable temperature range for the peanut canopy during the pod-in stage is $23-28{ }^{\circ} \mathrm{C}$. Within this temperature range the higher the temperature, the more pods are produced. The appropriate relative humidity in the pod-in stage is $70-80 \%[37]$. If the canopy is too dense, the light energy utilization rate will be reduced, the ventilation and air permeability of the canopy will be poor, water evaporation will be too slow, and the relative humidity will be too high, all of which are not conducive to plant growth. If the canopy is too sparse, the leaves receive too much light and the leaf water evaporation is high, and the relative humidity of the canopy is too low, all of which are also not conducive plant growth. When the critical value of the leaf area index of 5.5 is not exceeded, AMF treatment of peanut increases the number of leaves, leading to increased canopy density to a certain extent and making the canopy temperature and humidity more conducive to plant growth. AMF treatment affects plant canopy configuration, nutrient transport and its regulatory mechanisms. After AMF treatment, nutrient transport, canopy structure adjustment and hormone level distribution should be a systematic project. However, the interaction process remains poorly understood and needs further research.

\section{Conclusions}

Here, we have explored the effects of AMF treatment on the photosynthetic efficiency, and the dry matter accumulation and yield of peanut from the point view of canopy layer structure and we have reached the following main conclusions. 
First, AMF and peanut can form beneficial symbiotic relationships. AMF treatment increased nutrient uptake, growth, dry matter accumulation and yield of peanut. In addition, AMF treatment increased the height, canopy width and total leaf area of the plants. Compared with the control, the height, canopy width and total leaf area of peanut in the AMF treatment increased by 68.7, 49.7 and 71.1\%, respectively, after growth for 45 days, and by 178.7, 187.4 and $1020 \%$ after 70 days.

Second, AMF colonization improved the canopy structure of peanut. AMF reduced the leaf inclination and tiller angle of the upper layer while increasing the leaf inclination and tiller angle of the middle and lower layers as well as the average leaf area and leaf area index. In addition, the tiller angle of peanut in the AMF treatment showed the trend: upper layer < middle layer $<$ lower layer, while that in the control was not significantly different among layers. Moreover, the tiller angle in the upper and middle layers of peanut in the AMF treatment was significantly smaller than in the same layer of the controls. In addition, the height, canopy width and total leaf area were significantly positively correlated with production, while the tiller angles were significantly negatively correlated with production.

Third, AMF treatment changed the canopy structure and thus further affected photosynthesis. In detail, AMF treatment increased the net photosynthetic rate of leaves in the upper, middle and lower layers by 345,251 , and 204\%, respectively, at 45 days of growth, reaching a maximum.

We have only addressed the impact of AMF treatment on canopy structure and have not explored the effects of AMF treatment on root traits. Future research will include analysis of the correlation between canopy structure and the root system, and this should be important in the cultivation of peanut to give high yields. This type of study may help to guide farming practice in the ecological application of AMF in agriculture.

\section{Abbreviations}

LAI: leaf area index ;LAD: leaf angle distribution;AMF: arbuscular mycorrhizal fungi;WUE: water use efficiency.

\section{Declarations}




\section{Ethics approval and consent to participate}

Not applicable

\section{Consent for publication}

Not applicable

\section{Availability of data and materials}

Datasets used in the current study are available from the corresponding author on reasonable request.

\section{Competing interests}

The authors declare that they have no competing interests

\section{Funding}

This study was jointly supported by funds from the National Natural Science Foundation of China (51574253) and the Capital Science and Technology Talents Training Project (Beijing) (Z18110006318021).

\section{Authors' contributions}

BYL analyzed and interpreted the effect of AMF on the spatial structure and photosynthesis of plant canopy. ZHL set up experiments and collected data, and was a major contributor in writing the manuscript. Peter Christie modified and optimized the manuscript.All authors read and approved the final manuscript.

\section{Acknowledgements}

We are grateful to editors and reviewers for their valuable suggestions.

\section{References}

[1] Zelitch I. Close relationship between net photosynthesis and crop yield. Bioscience .1982; 32( 10): 796-802.

[2] Chang T-G, Zhao Hl, Wang N, et al.A three-dimensional canopy photosynthesis model in rice with a complete description of the canopy architecture, leaf physiology, and mechanical properties. Journal of Experimental Botany. 2019;70(9): 2479-2490.

[3] Wang Y H, Li J Y. Molecular basis of plant architecture. Annual Review of Plant Biology.2008;59: 253-279.

[4] Song Q, Chu C, Parry M A, Zhu X G. Genetics-based dynamic systems model of canopy photosynthesis: the key to improve light and resource use efficiencies for crops. Food 
and Energy Security.2016;5(1): 18-25.

[5] Wang X P, Fan W Y, Qu D.Relationship between leaf area index and leaf inclination distribution based on single line multi-angle measurement of plant canopy analyzer. Chinese Journal of Ecology. 2014;33(12): 3209-3215.

[6] Riczu P, Tamás J, Nagy A, Fórián T, Nagy G, Jancsó T, Nyéki J.3D laser scanning and modeling of single trees in Karcag Research Center. Analele Universitătii din Oradea, Fascicula Protectia Mediului. 2011;17: 277-284.

[7] Xiang Lr, Bao Y, Tang L, et al.Automated morphological traits extraction for sorghum plants via 3D point cloud data analysis. Computers and Electronics in Agriculture. 2019; 162: 951-961.

[8] Smith S E, Read D J. Mycorrhizal Symbiosis (Third Edition). Academic Press. 2008.

[9] Neagoe A, Iordache V, Bergmann H, et al. Patterns of effects of arbuscular mycorrhizal fungi on plants grown in contaminated soil. Journal of Plant Nutrition and Soil Science.2013;176(2): 273-286.

[10] Li W B, Lu W Q, Xie J W, et al. Effects of arbuscular mycorrhizal fungi on growth and physiology of cut tulips. Journal of Fungus. 2018;37(4): 456-465.

[11]Qiu L, Bi Y L, Jiang B, et al. Arbuscular mycorrhizal fungi ameliorate soil chemical properties and enzyme activities of rhizosphere soil in reclaimed mining subsidence in northwest China. Journal of arid Land.2019;11(1): 135-147

[12]Wu L S, Wang Y, Zhao Q H, et al. Effects of arbuscular mycorrhizal fungi on photosynthetic performance of tea leaves. Journal of Qingdao Agricultural University (Natural Science Edition).2011;28(01):13-15+23

[13] Sheng M, Tang M, Chen H, et al. Influence of arbuscular mycorrhizae on photosynthesis and water status of maize plants under salt stress. Mycorrhiza. 2008;18(6-7): 287-296.

[14]Bi Y L, Yu H Y, Yryszhan Z, et al. Effect of three-dimensional laser scanning on morphology of inoculated mycorrhizal plants. Journal of Coal.2016;41(8), 2071-2077.

[15]Xiao L, Bi Y L, Du S Z, et al. Effects of re-vegetation type and arbuscular mycorrhizal fungal inoculation on soil enzyme activities and microbial biomass in coal mining subsidence areas of northern China. Catena. 2019;177: 202-209 
1 [16]Bao S D. Analysis of Soil Agrochemistry. China Agriculture Press, 2000.

2 [17]Kormanik P P, Bryon W C, Schultz R C. Procedures and equipment for staining large number of plant root samples for endomycorrhizal assay. Canadian Journal of Microbiology.1980;26(4): 536-538.

[18]Paulus S, Dupuis J, Riedel S, et al. Automated analysis of barley organs using 3D: laser scanning: An approach for high throughput phenotyping. Sensors.2014;14: 12670-12686.

[19]Paulus S.Measuring crops in 3D using geometry for plant phenotyping. Plant Methods. 2019;15(1): 103.

[20]Zheng G, Moskal LM. Retrieving leaf area index (LAI) using remote sensing: Theories, methods and sensors. Sensors.2009;9(4): 2719-2745.

[21]Peng Z Y, Dan L, Zhang Z M, et al. peanut plant type and high yield. Journal of Peanut Science. 2019;48(2): 69-72.

[22] Lu Q, Liu H, Li H F, et al.Correlation analysis of main agronomic characters of peanut with different plant types and its effect on yield per plant. Journal of Tropical Crops. 2019;40(6): 1115-1121.

[23] Wang X L, Zhen Z G, Duan Y, et al. Relationship between peanut leaf area index growth and decline and yield. Journal of Anhui Agricultural Sciences.2003;31(6): 940-941.

[24] Sun Y H, Wang C B. Factors contributing to high yields of groundnut in Shandong, China. International Arachis Newsletter.1990;8: 7-9.

[25]Zheng P F,Yu X X, Jia G D, et al. Water use efficiency and its influencing factors of Pinus orientalis plantation in Beijing mountain area. Applied Ecology News.2019; 30(3):727-734.

[26]Jie Y L, Yang H Q,Cui M G, et al. Relationship between soil moisture content and water use efficiency of apple leaves. Applied Ecology News. 2001;(3):387-390.

[27]Wang Q, Chen J L, Sun Z Q. LAI-2000Application of canopy analyzer in study on light distribution characteristics of different plant populations. Chinese Agricultural Science.2006;39(5): 922-927.

[28]Guo H L, Liu S J, Xu J, et al. Effects of arbuscular mycorrhizal fungi on growth and root characteristics of dicotyledonous plants: Integration analysis. Chinese Journal of 
Ecology.2017;36(7): 1855-1864.

[29]Chen Y, Han B J. Effects of different soil nutrient areas on soybean canopy structure. Agricultural System Science and Comprehensive Research.2006;22(1): 17-20.

[30] Qu M H, Yu Y C, Li S, et al. Research progress on activation of mineral nutrients by arbuscular mycorrhizal fungi. Journal of Zhejiang Agriculture and Forestry University.2019;36(2): 187-198.

[31] Marschner H, Rimmington G.Mineral nutrition of higher plants. Plant Cell and Environment. 1988;11(2): 147-148.

[32] Jongen M, Fay P, Jones M B. Effects of elevated carbon dioxide and arbuscular mycorrhizal infection on Trifolium repens. New Phytologist.1996;132(3): 413-423.

[33]Paul M J, Foyer C H. Sink regulation of photosynthesis. Journal of Experimental Botany.2001;52(360): 1383-1400.

[34] Wu Q S, Zou Y N, He X H, et al. Arbuscular mycorrhizal fungi can alter some root characters and physiological status in trifoliate orange (Poncirus trifoliata L. Raf.) seedlings. Plant Growth Regulation.2011;65(2): 273-278.

[35]Kaschuk G, Kuyper T W, Leffelaar P A, et al. Are the rates of photosynthesis stimulated by the carbon sink strength of rhizobial and arbuscular mycorrhizal symbioses?. Soil Biology and Biochemistry.2009;41(6): 1233-1244.

[36] Al-Karaki G N.Growth of mycorrhizal tomato and mineral acquisition under salt stress. Mycorrhiza. 2000;10: 51-54.

[37]Wan S B. Peanut Science and Technology. Shanghai: Shanghai Science and Technology Press (in Chinese).2003. 
Table 1 Effects of AMF treatment on uncomplicated characteristics of the peanut canopy

\begin{tabular}{|c|c|c|c|c|c|c|}
\hline Treatment & \multicolumn{2}{|c|}{ Day 30} & \multicolumn{2}{|c|}{ Day 45} & \multicolumn{2}{|c|}{ Day 70} \\
\hline $\begin{array}{l}\text { Plant height } \\
(\mathrm{mm})\end{array}$ & $89.5 \pm 3.01 \mathrm{c}$ & $85.6 \pm 4.71 \mathrm{c}$ & $164 \pm 13.7 b$ & $97.0 \pm 4.38 \mathrm{c}$ & $292 \pm 21.57 \mathrm{a}$ & $105 \pm 6.28 \mathrm{c}$ \\
\hline $\begin{array}{l}\text { Canopy diameter } \\
(\mathrm{mm})\end{array}$ & $190.3 \pm 4.80 \mathrm{c}$ & $190.2 \pm 6.39 c$ & $271 \pm 15.12 b$ & $181 \pm 3.71 \mathrm{c}$ & $510 \pm 22.04 a$ & $178 \pm 9.24 c$ \\
\hline $\begin{array}{l}\text { Total leaf area } \\
\left(\mathrm{mm}^{2}\right)\end{array}$ & $16928 \pm 1450 \mathrm{c}$ & $14637 \pm 1790 \mathrm{c}$ & $47940 \pm 4955 b$ & $17682 \pm 1759 \mathrm{c}$ & $165697 \pm 12847 \mathrm{a}$ & $14796 \pm 1066 c$ \\
\hline
\end{tabular}


Table 2 Effects of AMF treatment on complex characteristics of the canopy

\begin{tabular}{|c|c|c|c|c|c|c|c|}
\hline \multirow{2}{*}{ Measurement } & \multirow{2}{*}{ Layer/treatment } & \multicolumn{2}{|c|}{ Day 30} & \multicolumn{2}{|c|}{ Day 45} & \multicolumn{2}{|c|}{ Day 70} \\
\hline & & $\mathrm{AM}$ & $\mathrm{CK}$ & $\mathrm{AM}$ & $\mathrm{CK}$ & $\mathrm{AM}$ & $\mathrm{CK}$ \\
\hline \multirow{3}{*}{ Tiller angle $\left(^{\circ}\right)$} & Upper layer & $71.1 \pm 2.56 b$ & $83.0 \pm 1.78 \mathrm{a}$ & $37.5 \pm 4.0 \mathrm{e}$ & $61.9 \pm 2.8 \mathrm{c}$ & $47.7 \pm 2.86 \mathrm{~d}$ & $39.0 \pm 2.08 \mathrm{e}$ \\
\hline & Intermediate layer & l & l & $46.3 \pm 3.1 \mathrm{c}$ & $68.9 \pm 1.5 \mathrm{a}$ & $44.01 \pm 2.02 \mathrm{c}$ & $57.5 \pm 4.52 b$ \\
\hline & Lower layer & $64.0 \pm 1.48 b c$ & $60.6 \pm 5.57 b c$ & $75.2 \pm 4.12 \mathrm{a}$ & $63.5 \pm 3.17 \mathrm{ab}$ & $40.86 \pm 2.41 d$ & $56.5 \pm 2.92 \mathrm{c}$ \\
\hline \multirow{3}{*}{ Leaf angle $\left(^{\circ}\right)$} & Upper layer & $43.8 \pm 2.78 \mathrm{ab}$ & $38.5 \pm 2.66 \mathrm{bc}$ & $33.06 \pm 4.78 \mathrm{c}$ & $48.2 \pm 3.87 \mathrm{a}$ & $17.18 \pm 2.0 \mathrm{~d}$ & $32.4 \pm 2.77 \mathrm{c}$ \\
\hline & Intermediate layer & l & l & $36.3 \pm 0.99 \mathrm{ab}$ & $40.0 \pm 2.85 \mathrm{a}$ & $30.3 \pm 1.83 b c$ & $25.7 \pm 3.30 \mathrm{c}$ \\
\hline & Lower layer & $40.9 \pm 3.26 \mathrm{a}$ & $35.2 \pm 3.06 \mathrm{ab}$ & $\begin{array}{c}28.3 \pm 1.81 b c \\
d\end{array}$ & $30.0 \pm 1.99 b c$ & $22.1 \pm 1.82 \mathrm{~d}$ & $23.2 \pm 3.30 \mathrm{~cd}$ \\
\hline \multirow{3}{*}{$\begin{array}{l}\text { Mean leaf area } \\
\left(\mathrm{mm}^{2}\right)\end{array}$} & Upper layer & $581 \pm 34.1 b c$ & $639 \pm 31.1 b c$ & $699 \pm 51.0 \mathrm{~b}$ & $546 \pm 82.1 \mathrm{c}$ & $1258 \pm 47.3 \mathrm{a}$ & $325 \pm 38.6 \mathrm{~d}$ \\
\hline & Intermediate layer & 1 & I & $395 \pm 33.9 c$ & $532 \pm 37.1 \mathrm{~b}$ & $786 \pm 65.3 \mathrm{a}$ & $374 \pm 26.9 \mathrm{c}$ \\
\hline & Lower layer & $491 \pm 28.4 b$ & $376 \pm 29.0 \mathrm{c}$ & $633 \pm 27.7 \mathrm{a}$ & $398 \pm 35.4 b c$ & $639 \pm 49.5 \mathrm{a}$ & $142 \pm 15.9 \mathrm{~d}$ \\
\hline
\end{tabular}


Table 3 Effects of AMF treatment on leaf area index

\begin{tabular}{ccccccc}
\hline Time & \multicolumn{2}{c}{ Day 30} & & Day 45 & & Day 70 \\
\hline Treatment & AM & CK & AM & CK & AM & CK \\
\hline $\begin{array}{c}\text { Leaf area } \\
\text { index }\end{array}$ & $1.59 \pm 0.04 \mathrm{~b}$ & $1.59 \pm 0.09 \mathrm{~b}$ & $1.91 \pm 0.17 \mathrm{a}$ & $1.77 \pm 0.07 \mathrm{ab}$ & $1.78 \pm 0.03 \mathrm{ab}$ & $1.70 \pm 0.06 \mathrm{ab}$ \\
\hline
\end{tabular}

2 Leaf area index $=$ Total leaf area $\left(\mathrm{mm}^{2}\right) /$ Blade projected area $\left(\mathrm{mm}^{2}\right)$. 
Table 4 Net photosynthetic rate under different treatments at different layers and time periods in $\mu \mathrm{mol} \mathrm{m}{ }^{-2} \mathrm{~s}^{-1}$

\begin{tabular}{l|ccccccc}
\multirow{2}{*}{ Layer } & \multicolumn{2}{|c}{ Day 30} & \multicolumn{2}{c}{ Day 45} & & Day 70 & \\
\cline { 2 - 8 } & AM & CK & AM & CK & AM & CK \\
\hline Upper & $7.25 \pm 0.73 \mathrm{c}$ & $6.17 \pm 0.77 \mathrm{c}$ & $16.0 \pm 1.33 \mathrm{a}$ & $5.74 \pm 0.44 \mathrm{c}$ & $12.8 \pm 0.81 \mathrm{~b}$ & $7.83 \pm 0.98 \mathrm{c}$ \\
\hline Intermediate & $/$ & $/$ & $15.4 \pm 0.90 \mathrm{a}$ & $4.39 \pm 0.58 \mathrm{c}$ & $10.5 \pm 0.88 \mathrm{~b}$ & $4.92 \pm 1.00 \mathrm{c}$ \\
\hline Lower & $6.09 \pm 0.68 \mathrm{bc}$ & $4.66 \pm 0.96 \mathrm{bc}$ & $10.8 \pm 1.38 \mathrm{a}$ & $3.58 \pm 0.56 \mathrm{c}$ & $7.57 \pm 1.15 \mathrm{~b}$ & $5.84 \pm 0.99 \mathrm{bc}$ \\
\hline
\end{tabular}




\begin{tabular}{|c|c|c|c|c|c|c|}
\hline Layer & \multicolumn{2}{|c|}{ Upper layer } & \multicolumn{2}{|c|}{ Middle layer } & \multicolumn{2}{|c|}{ Lower layer } \\
\hline $\begin{array}{l}\text { Net } \\
\text { photosynthetic } \\
\text { rate }\end{array}$ & $16.0 \pm 1.33 \mathrm{a}$ & $5.74 \pm 0.44 c$ & $15.4 \pm 0.9 \mathrm{a}$ & $4.39 \pm 0.58 \mathrm{c}$ & $10.8 \pm 1.38 b$ & $3.58 \pm 0.56 \mathrm{c}$ \\
\hline $\begin{array}{l}\text { Intercellular } \\
\mathrm{CO}_{2} \\
\text { concentration }\end{array}$ & $269 \pm 8.14 b$ & $320 \pm 5.55 \mathrm{a}$ & $278 \pm 5.32 b$ & $245 \pm 7.1 c$ & $280 \pm 5.81 b$ & $244 \pm 6.74 c$ \\
\hline $\begin{array}{l}\text { Water use } \\
\text { efficiency }\end{array}$ & $1.68 \pm 0.1 \mathrm{c}$ & $2.92 \pm 0.14 \mathrm{a}$ & $1.55 \pm 0.06 \mathrm{c}$ & $1.82 \pm 0.08 b$ & $1.49 \pm 0.07 \mathrm{c}$ & $1.84 \pm 0.1 b$ \\
\hline
\end{tabular}


Table 6 Nutrients accumulated in the roots, stems and leaves

\begin{tabular}{lcccccc}
\hline Measurement & \multicolumn{2}{c}{ Nitrogen $(\mathrm{mg})$} & & Phosphorus (mg) & & Potassium (mg) \\
\hline Plant & AM & CK & AM & CK & AM & CK \\
part/treatment & & & & & & \\
\hline Leaves & $112 \pm 13.6 \mathrm{a}$ & $7.07 \pm 1.51 \mathrm{~b}$ & $2.58 \pm 0.42 \mathrm{a}$ & $0.05 \pm 0.02 \mathrm{~b}$ & $5.75 \pm 1.16 \mathrm{a}$ & $0.41 \pm 0.18 \mathrm{~b}$ \\
\hline Stems & $70.4 \pm 13.94 \mathrm{a}$ & $30.1 \pm 2.58 \mathrm{~b}$ & $1.38 \pm 0.21 \mathrm{a}$ & $0.35 \pm 0.07 \mathrm{~b}$ & $4.72 \pm 0.91 \mathrm{a}$ & $1.13 \pm 0.22 \mathrm{~b}$ \\
\hline Roots & $22.4 \pm 1.56 \mathrm{a}$ & $20.1 \pm 3.9 \mathrm{a}$ & $0.44 \pm 0.05 \mathrm{a}$ & $0.28 \pm 0.1 \mathrm{a}$ & $0.73 \pm 0.13 \mathrm{a}$ & $1.10 \pm 0.55 \mathrm{a}$ \\
\hline
\end{tabular}

2 Nutrients accumulated in each plant parts $(\mathrm{mg})=$ concentration of nutrient in each plant part $\left(\mathrm{mg} \mathrm{kg}^{-1}\right) \times$ dry weight of the plant part $(\mathrm{g}) \times 10^{-3}$. 
Table 7 Effects of AMF on plant dry matter accumulation and yield

\begin{tabular}{lccc}
\hline Treatment & Aboveground parts $(\mathrm{g})$ & Belowground parts $(\mathrm{g})$ & Production $(\mathrm{g})$ \\
\hline $\mathrm{AM}$ & $15.6 \pm 1.69 \mathrm{a}$ & $7.88 \pm 1.18 \mathrm{a}$ & $6.49 \pm 1.16 \mathrm{a}$ \\
\hline $\mathrm{CK}$ & $1.90 \pm 0.18 \mathrm{~b}$ & $0.95 \pm 0.17 \mathrm{~b}$ & $0.02 \pm 0.01 \mathrm{~b}$ \\
\hline
\end{tabular}

2 
Table 8 Correlation between canopy structure and production

\begin{tabular}{llllllll}
\hline $\begin{array}{l}\text { Production/canopy } \\
\text { structure index }\end{array}$ & Plant height & Crown & $\begin{array}{l}\text { Total blade } \\
\text { area }\end{array}$ & Leaf area index & Leaf angle & $\begin{array}{l}\text { Mean blade } \\
\text { area }\end{array}$ & $\begin{array}{l}\text { Transpiration } \\
\text { rate }\end{array}$ \\
\hline Production & $0.720^{*}$ & $0.711^{*}$ & $0.748^{*}$ & 0.248 & 0.650 & 0.462 & -0.425 \\
\hline
\end{tabular}

$2 \quad * *, \mathrm{P}<0.01 ; *, \mathrm{P}<0.05 ; \mathrm{n}=16$. 


\section{$1 \quad$ Figure legends}

2

3 Fig. 1 Stratification of stem structure in canopy of peanut; (a) AMF treatment; (b) control

4

5 Fig. 2 Top view and side view of canopy of peanut treated differently after growth for 45 days; (a) side

6 view of processing; (b) side view of control; (c) top view of AMF treatment; (d) top view of control

7

8 Note: The pictures were produced by the Geomagic software by the author of this article, so this article 9 has access to the pictures. 
Figures

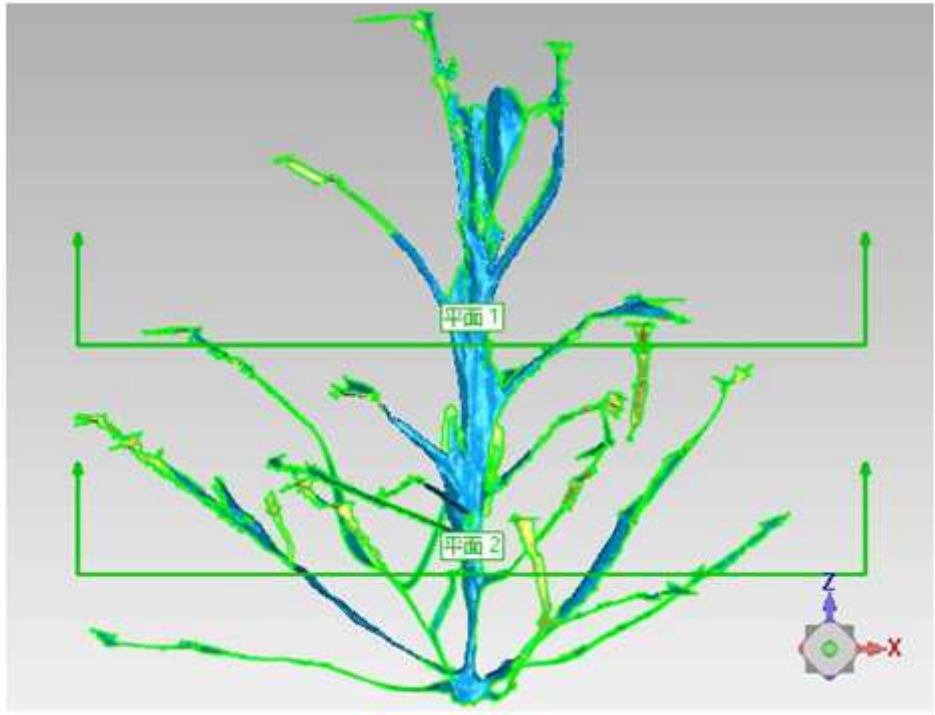

(a)

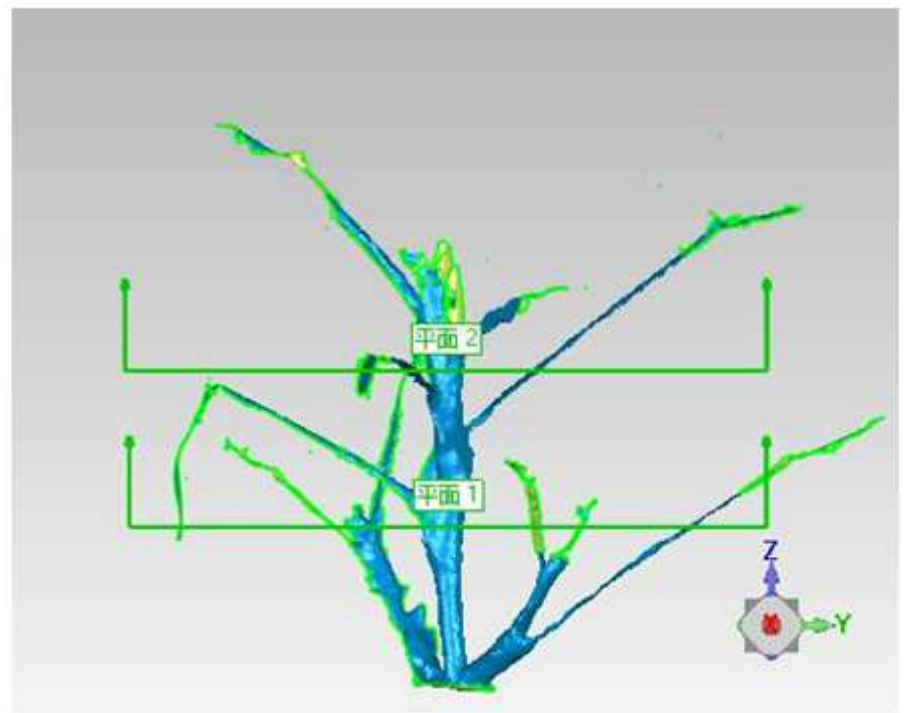

(b)

Figure 1

Stratification of stem structure in canopy of peanut; (a) AMF treatment; (b) control 


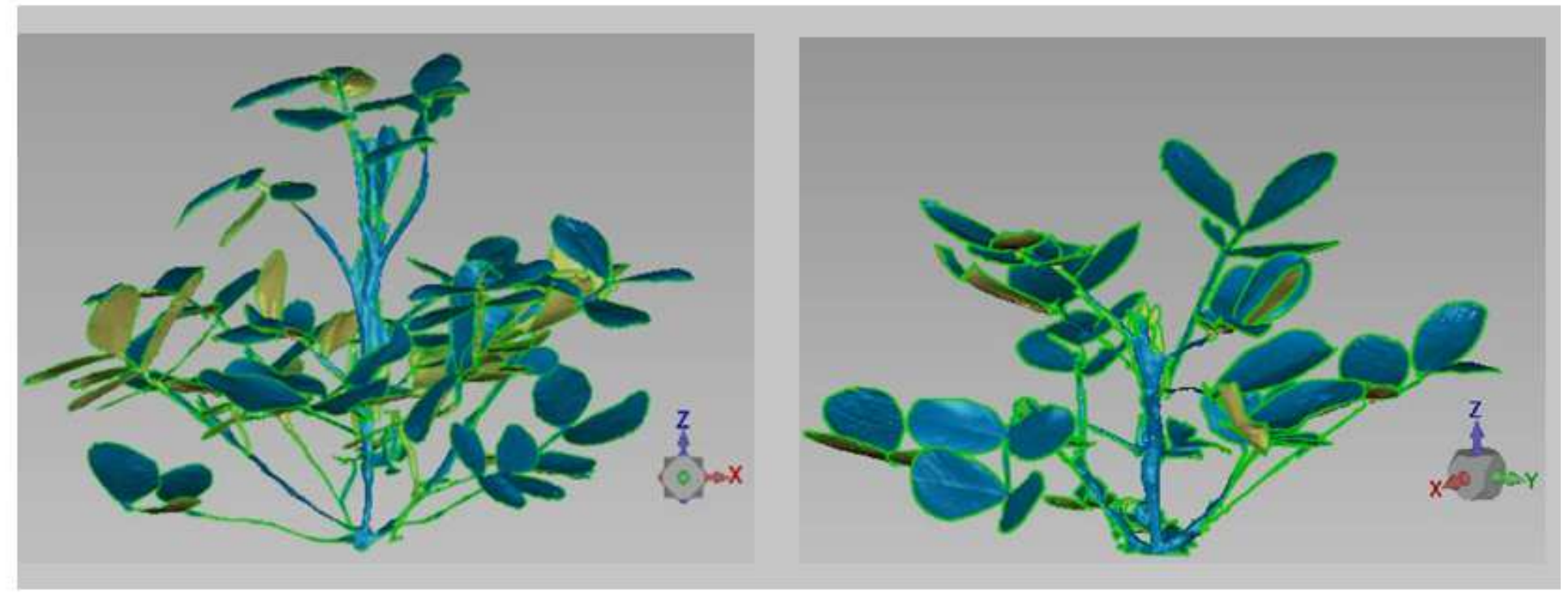

(a)

(b)
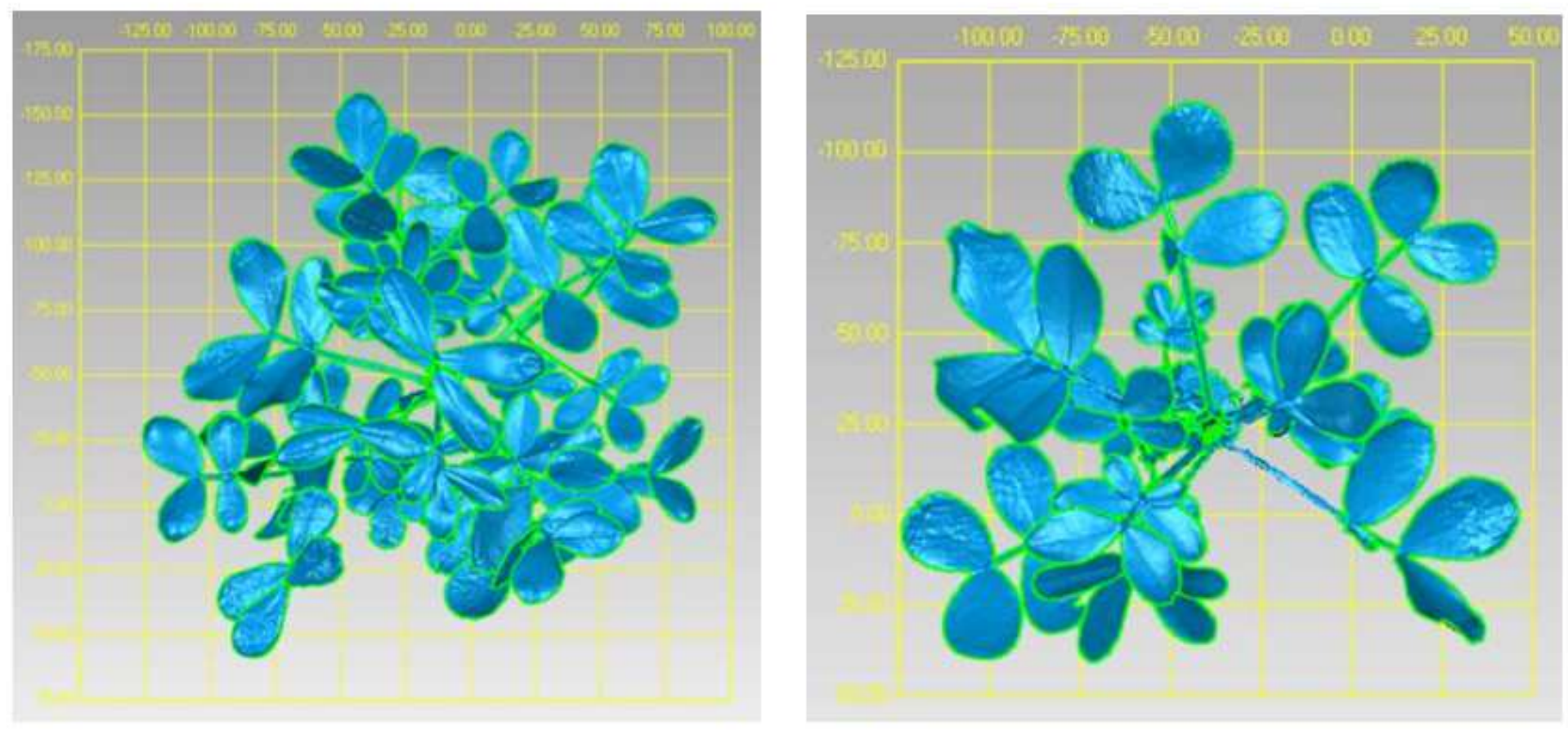

(c)

(d)

\section{Figure 2}

Top view and side view of canopy of peanut treated differently after growth for 45 days; (a) side view of processing; (b) side view of control; (c) top view of AMF treatment; (d) top view of control. 